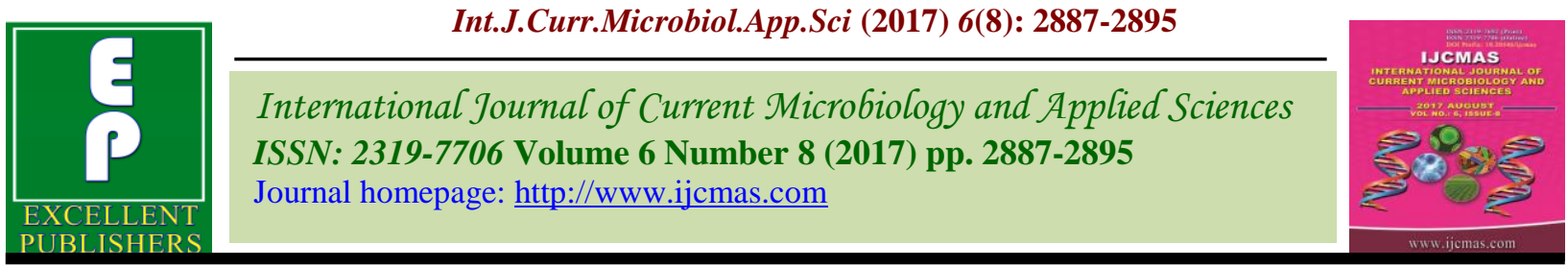

Original Research Article

https://doi.org/10.20546/ijcmas.2017.608.345

\title{
Maize Price Forecasting Using Auto Regressive Integrated Moving Average (ARIMA) Model
}

\author{
Venkatesh Panasa*, R. Vijaya Kumari, G. Ramakrishna and S. Kaviraju
}

Department of Agricultural Economics, College of Agriculture, Professor Jayashankar

Telangana State Agricultural University, Hyderabad-500030, Telangana, India

*Corresponding author

\section{A B S T R A C T}

Keywords

Maize prices,

Stationarity,

Differencing,

ARIMA, MAPE

and Price forecast.

Article Info

Accepted:

23 June 2017

Available Online:

10 August 2017
This paper examined the monthly modal prices of maize using Autoregressive Integrated Moving Average (ARIMA) models so as to determine the most efficient and adequate model for analyzing the maize monthly modal prices in Telangana. The results indicate that Autoregressive Integrated Moving Average ARIMA 211 model is the most adequate and efficient model. This was ascertained by comparing the various model selection criterion and the diagnostic tests for various models among them Akaike Information Criteria (AIC) and Bayesian Information Criteria (BIC) and Mean Absolute Percentage Error (MAPE). Time series Analysis was done using SAS 9.3 software. A better understanding of maize price situation and future prices will facilitate farmers and end users to make appropriate decisions regarding buying and selling patterns hence government should take adequate policies. The forecasted results suggest that there are expectations of increasing maize prices in Badepalli market next five months (October to February). This requires the government to take appropriate measures to ensure that farmers and end user get benefited.

\section{Introduction}

Agriculture is the mainstay in Telangana, as more than half of the State's population depends on it for their livelihood. A stable and high growth in agriculture sector is essential for uplifting the standard of living of rural population. Maize is one of the important coarse cereal crops grown in different agro-climatic conditions of India. Maize ranks third next to wheat and rice in the world with respect to area, while its productivity surpasses all other cereal crops. Maize is grown in 70 countries of the world. The major maize growing countries are USA, China, Brazil, Mexico, Indonesia, India,
France and Argentina. India is at $6^{\text {th }}$ position in Maize production and $15^{\text {th }}$ position in its productivity in the World. In India maize is grown all over the country. In India the major producing states are Karnataka, Andhra Pradesh, Madhya Pradesh, Bihar, Rajasthan, Tamil Nadu, Telangana and Uttar Pradesh. In 2015-16 Karnataka is the largest maize producing state in India with a production of 3.01 million tonnes and Andhra Pradesh is next to the Karnataka in case of production with a production of 2.76 million tonnes. In case of area Karnataka stands first and Andhra Pradesh ranks fifth next to Rajasthan, 
Madhya Pradesh and Maharashtra with an area of 0.78 million hectares. Maize is a traditional crop of Telangana state. In India maize stands fifth in area and second in terms of production and productivity. The area, production and productivity of maize in Telangana are increasing. The main objective of this study was to forecast the maize monthly modal prices using Autoregressive integrated Moving Average (ARIMA) model. The study was guided by the following specific objectives; to fit an ARIMA to the data on the prices of maize and evaluate the efficiency of the ARIMA model on forecasting the maize prices in Telangana.

Praneshu et al., (2002) in their study found that structural time series modeling is best model over ARIMA model to predict observations that are regarded as made up of distinct component such as trend and cyclical fluctuations. The techniques that emerge from this approach are extremely flexible and are capable of handling a much wider range of problem than is possible through ARIMA approach. Bharathi et al., (2009) studied forecasting of arrivals and prices of cocoons in Ramnagar market.

ARIMA model was used for forecasting of arrivals and prices. Suitable model was identified based on the ACF and PACF. The adequacy of the model was udged based on Akaike Information criterion and Mean Square Error. Model ARIMA113, ARIMA111 was identified for price forecasting. Forecasted values of arrivals showed increasing trend in both the market and price showed decreasing trend in sidlaghatta market.

A practical treatment on ARIMA modeling along with several case studies can be found in Pankratz (1983). A reference book on ARIMA and related topics with a more rigorous theoretical flavour is by Box et al.,
(1994). Paul and Das (2010) applied ARIMA model for modeling and forecasting of inland fish production in India.

\section{Data source}

The average monthly modal maize price data were collected from Badepalli regulated market about 16 years from April 2002 to May 2017 was used for price forecasting, data were collected from the official website of agricultural marketing department of Telangana state http://agrimarketing. telangana.gov.in/ formed the source of secondary information on prices of maize. The major criterion for market selection is based on the arrivals.

\section{Materials and Methods}

\section{Stationarity}

The noise (or residual) series for an ARMA model must be stationary, which means that both the expected values of the series and its auto covariance function are independent of time. The standard way to check for non stationarity is to plot the series and its autocorrelation function. You can visually examine a graph of the series over time to see if it has a visible trend or if its variability changes noticeably over time. If the series is non stationary, its autocorrelation function will usually decay slowly. Another way of checking for stationarity is to use the stationarity tests. Most time series are nonstationary and must be transformed to a stationary series before the ARIMA modeling process can proceed.

\section{Autocorrelation function (ACF) and partial autocorrelation function (PACF)}

Theoretical ACFs and PACFs (Autocorrelations versus lags) are available for the various models chosen (say, see 
Pankratz, 1983) for various values of orders of autoregressive and moving average components i.e. $\mathrm{p}$ and $\mathrm{q}$. Thus compare the correlograms (plot of sample ACFs versus lags) obtained from the given TS data with these theoretical $\mathrm{ACF} / \mathrm{PACF}$, to find a reasonably good match and tentatively select one or more ARIMA models. The general characteristics of theoretical ACFs and PACFs are as follows:-(here 'spike' represents the line at various lags in the plot with length equal to magnitude of autocorrelations)

\section{Differencing}

A deterministic seasonal pattern will also cause the series to be non-stationary, since the expected value of the series will not be the same for all time periods but will be higher or lower depending on the season. When the series has a seasonal pattern, you may want to difference the series at a lag corresponding to the length of the cycle of seasons. To take a second difference, add another differencing period to the list. There is no limit to the order of differencing and the degree of lagging for each difference.

\section{Auto Regressive Integrated Moving Average (ARIMA)}

The Box-Jenkins models are especially suited to short term forecasting because most ARIMA models place greater emphasis on the recent past rather than the distant past.

The Box-Jenkins method applies to both discrete data as well as to continuous data. However, the data should be available at equally spaced discrete time intervals. Also, building of a ARIMA model requires a minimum of about 40-50 observations. This process is an amalgamation to ARMA process when the time series $\{\mathrm{Yt}\}$ is Non-Stationary or "Integrated". It is obvious that to develop the ARMA model in this situation, the series has to be "differenced" to make it stationary and this differenced series, which is now stationary has to be subjected to fitting of ARMA model.

This process is referred as ARIMA (p, d, q), where $p$ and $q$ refer to the number of AR and MA terms and $d$ refers to the order of differencing required for making the series a Stationary. The characteristics of the time series models, i.e., the parameters (p, d, q) and thereafter the estimation of the relevant model can be carried out in a planned approach outlined by Box and Jenkins methodology.

The methodology involves the following four steps

Identification of the characteristics (p, d, q) for the Model

Estimation

Diagnostics Checking

Forecasting

Identification of the characteristics (p, d, q) for the model

The foremost step in the process of modeling is to check for the stationarity of the series, as the estimation procedures are available only for stationary series.

If the original series is non stationary then first of all it should be made stationarity.

\section{Estimation}

On the basis of identification of the parameters $(\mathrm{p}, \mathrm{d}, \mathrm{q})$ the series is subjected to fitting of the appropriate ARIMA (p, d, q) model. The procedure for fitting the model 
involves transforming the series through appropriate differencing, in case it is nonstationary, and then subjecting the differenced series to fitting. Choice of parameters on the basis of significant ACFs and PACFs.

\section{Diagnostics}

Low Akaike Information Criteria (AIC)/ Bayesian Information Criteria (BIC)/ Schwarz-Bayesian Information Criteria (SBC)

AIC is given by $(-2 \log \mathrm{L}+2 \mathrm{~m})$ where $\mathrm{m}=\mathrm{p}+$ $\mathrm{q}+\mathrm{P}+\mathrm{Q}$ and $\mathrm{L}$ is the likelihood function. Since $-2 \log \mathrm{L}$ is approximately equal to $\{\mathrm{n}$ $\left.(1+\log 2 \pi)+\mathrm{n} \log \sigma^{2}\right\}$ where $\sigma^{2}$ is the model MSE, Thus AIC can be written as $\mathrm{AIC}=\{\mathrm{n}$ $\left.(1+\log 2 \pi)+n \log \sigma^{2}+2 m\right\}$ and because first term in this equation is a constant, it is usually omitted while comparing between models. As an alternative to AIC, sometimes SBC is also used which is given by $\mathrm{SBC}=\log \sigma^{2}+(\mathrm{m} \log$ n) $/$ n.

\section{Plot of residual ACF}

Once the appropriate ARIMA model has been fitted, one can examine the goodness of fit by means of plotting the ACF of residuals of the fitted model.

If most of the sample autocorrelation coefficients of the residuals are within the limits $\pm 1.96 / \neg N$ where $\mathrm{N}$ is the number of observations upon which the model is based then the residuals are white noise indicating that the model is a good fit.

\section{Forecasting}

The model that satisfies all the diagnostic checks is considered for forecasting.

\section{Results and Discussion}

\section{Testing stationarity}

Stationarity tests can be performed to identify whether differencing is necessary. To check the stationarity of price series of maize, the Augmented Dickey Fuller unit root tests were used.

It is observed from the table that original series at level with lag 1, the ADF values are below the critical value at 5\% level of significance indicating that no existence of unit root, hence differencing at level with lag 1 , the ADF values are above the critical value at $5 \%$ level of significance indicating the existence of unit root.

From the above table 5, we can see the moving average (MA1) model, autoregressive $(A R 1,2)$ models are significant at $1 \%$ level of significance.

Among the different ARIMA models ARIMA 211 model have low Akaike Information Criteria (AIC) and Bayesian Information Criteria (BIC) and Mean Absolute Percentage Error (MAPE) as 1973.24, 1979.76 and 2.1 respectively and parameters are significant at $1 \%$ level of significance, hence maize monthly modal prices are forecasted with ARIMA 211 model.

Autocorrelation function (ACF) and partial autocorrelation function (PACF)

\begin{tabular}{|l|l|l|}
\hline Model & ACF & PACF \\
\hline AR & Spikes decay towards zero & Spikes cutoff to zero \\
\hline MA & Spikes cutoff to zero & Spikes decay to zero \\
\hline ARMA & Spikes decay to zero & Spikes decay to zero \\
\hline
\end{tabular}


Table.1 Original series of the maize monthly modal price data

\begin{tabular}{|l|r|r|r|r|r|r|r|}
\hline \multicolumn{7}{|c|}{ Augmented Dickey-Fuller Unit Root Tests } \\
\hline Type & Lags & Rho & Pr $<$ Rho & Tau & Pr $<$ Tau & F & Pr > F \\
\hline Zero Mean & $\mathbf{6}$ & 0.9318 & 0.8999 & 2.41 & $\mathbf{0 . 9 9 6 3}$ & & \\
\hline & $\mathbf{8}$ & 0.9288 & 0.8993 & 3.09 & $\mathbf{0 . 9 9 9 5}$ & & \\
\hline Single Mean & $\mathbf{6}$ & 0.2303 & 0.9671 & 0.20 & $\mathbf{0 . 9 7 2 3}$ & 3.12 & 0.2762 \\
\hline & $\mathbf{8}$ & 0.4501 & 0.9751 & 0.53 & $\mathbf{0 . 9 8 7 4}$ & 4.95 & 0.0403 \\
\hline Trend & $\mathbf{6}$ & -16.8214 & 0.1204 & -2.88 & $\mathbf{0 . 1 7 0 6}$ & 4.56 & 0.2663 \\
\hline & $\mathbf{8}$ & -11.5811 & 0.3258 & -2.59 & $\mathbf{0 . 2 8 7 3}$ & 4.00 & 0.3771 \\
\hline
\end{tabular}

Table.2 Differenced series of the maize monthly modal price data

\begin{tabular}{|l|r|r|r|r|r|r|r|}
\hline \multicolumn{7}{|c|}{ Augmented Dickey-Fuller Unit Root Tests } \\
\hline Type & Lags & Rho & Pr < Rho & Tau & Pr < Tau & F & Pr > F \\
\hline Zero Mean & $\mathbf{6}$ & 312.6686 & 0.9999 & -6.56 & $<.0001$ & & \\
\hline & $\mathbf{8}$ & 776.1659 & 0.9999 & -4.96 & $<.0001$ & & \\
\hline Single Mean & $\mathbf{6}$ & 195.7594 & 0.9999 & -7.24 & $<.0001$ & 26.20 & 0.0010 \\
\hline & $\mathbf{8}$ & 165.9125 & 0.9999 & -5.76 & $<.0001$ & 16.60 & 0.0010 \\
\hline Trend & $\mathbf{6}$ & 186.6796 & 0.9999 & -7.30 & $<.0001$ & 26.67 & 0.0010 \\
\hline & $\mathbf{8}$ & 151.9159 & 0.9999 & -5.85 & $<.0001$ & 17.10 & 0.0010 \\
\hline
\end{tabular}

Table.3 Autocorrelation check for white noise

\begin{tabular}{|r|r|r|r|r|r|r|r|r|r|}
\hline \multicolumn{9}{|c|}{ Autocorrelation Check for White Noise } \\
\hline To Lag & Chi-Square & DF & Pr > ChiSq & \multicolumn{5}{|c|}{ Autocorrelations } \\
\hline $\mathbf{6}$ & 39.81 & 6 & $<.0001$ & -0.376 & 0.105 & 0.017 & -0.245 & 0.031 & 0.035 \\
\hline $\mathbf{1 2}$ & 59.48 & 12 & $\mathbf{< . 0 0 0 1}$ & -0.129 & 0.056 & 0.119 & -0.137 & 0.214 & -0.058 \\
\hline $\mathbf{1 8}$ & 66.21 & 18 & $<.0001$ & -0.105 & 0.024 & -0.105 & 0.101 & 0.031 & 0.011 \\
\hline $\mathbf{2 4}$ & 69.65 & 24 & $\mathbf{< . 0 0 0 1}$ & 0.067 & -0.067 & -0.001 & -0.077 & 0.040 & 0.008 \\
\hline
\end{tabular}

In this case, white noise is rejected as a p-value for all lags less than o 0.05 . This is considered as a good fit model. 
Int.J.Curr.Microbiol.App.Sci (2017) 6(8): 2887-2895

Table.4 Conditional least squares estimation

\begin{tabular}{|c|c|c|c|c|c|}
\hline \multicolumn{7}{|c|}{ Conditional Least Squares Estimation } \\
\hline Parameter & Estimate & $\begin{array}{c}\text { Standard } \\
\text { Error }\end{array}$ & $\mathbf{t}$ Value & $\begin{array}{c}\text { Approx } \\
\text { Pr }>|\mathbf{t}|\end{array}$ & Lag \\
\hline MU & 5.20207 & 2.94948 & 1.76 & $\mathbf{0 . 0 7 9 5}$ & 0 \\
\hline MA1,1 & -0.80540 & 0.25973 & -3.10 & $\mathbf{0 . 0 0 2 2}$ & 1 \\
\hline AR1,1 & -1.19695 & 0.25335 & -4.72 & $<.0001$ & 1 \\
\hline AR1,2 & -0.36286 & 0.09330 & -3.89 & $\mathbf{0 . 0 0 0 1}$ & 2 \\
\hline
\end{tabular}

Table.5 AIC, SBC and MAPE values of different ARIMA models

\begin{tabular}{|l|l|l|l|l|l|l|l|}
\hline S. No. & $\begin{array}{l}\text { ARIMA } \\
\text { Models }\end{array}$ & $\begin{array}{l}\text { Constant } \\
\text { Estimate }\end{array}$ & $\begin{array}{l}\text { Variance } \\
\text { Estimate }\end{array}$ & $\begin{array}{l}\text { Std Error } \\
\text { Estimate }\end{array}$ & AIC & SBC & MAPE \\
\hline 1 & 111 & 6.68 & 3168.60 & 56.29 & 1975.68 & 1985.27 & 2.5 \\
\hline 2 & 011 & 5.17 & 3164.55 & 56.25 & 1974.46 & 1980.86 & 3.0 \\
\hline 3 & 110 & 7.16 & 3157.70 & 56.19 & 1973.95 & 1980.35 & 2.3 \\
\hline 4 & 210 & 7.45 & 3167.99 & 56.28 & 1975.64 & 1985.24 & 3.1 \\
\hline 5 & 112 & 6.73 & 3186.46 & 56.44 & 1977.67 & 1990.47 & 2.4 \\
\hline $\mathbf{6}$ & $\mathbf{2 1 1}$ & $\mathbf{1 3 . 3 1}$ & $\mathbf{3 1 5 6 . 5 7}$ & $\mathbf{5 6 . 1 8}$ & $\mathbf{1 9 7 3 . 2 4}$ & $\mathbf{1 9 7 9 . 7 6}$ & $\mathbf{2 . 1}$ \\
\hline
\end{tabular}

Table.6 Forecasts of maize monthly modal prices

\begin{tabular}{|r|c|c|c|c|}
\hline \multicolumn{5}{|c|}{ Forecasts for variable $\mathbf{~}$} \\
\hline Obs & Forecast & Std Error & \multicolumn{2}{c|}{$\mathbf{9 5 \%}$ Confidence Limits } \\
\hline October & $\mathbf{1 4 9 6 . 3 0 1 2}$ & 56.1834 & 1386.1837 & 1606.4187 \\
\hline November & $\mathbf{1 5 0 0 . 9 9 1 6}$ & 65.7662 & 1372.0921 & 1629.8910 \\
\hline December & $\mathbf{1 5 0 2 . 7 7 8 7}$ & 77.0426 & 1351.7780 & 1653.7794 \\
\hline January & $\mathbf{1 5 1 2 . 2 5 3 9}$ & 87.2713 & 1341.2052 & 1683.3026 \\
\hline February & $\mathbf{1 5 1 3 . 5 8 0 4}$ & 95.1065 & 1327.1751 & 1699.9857 \\
\hline
\end{tabular}


Fig.1 Before differencing maize price data

\section{Before differencing maize price data}
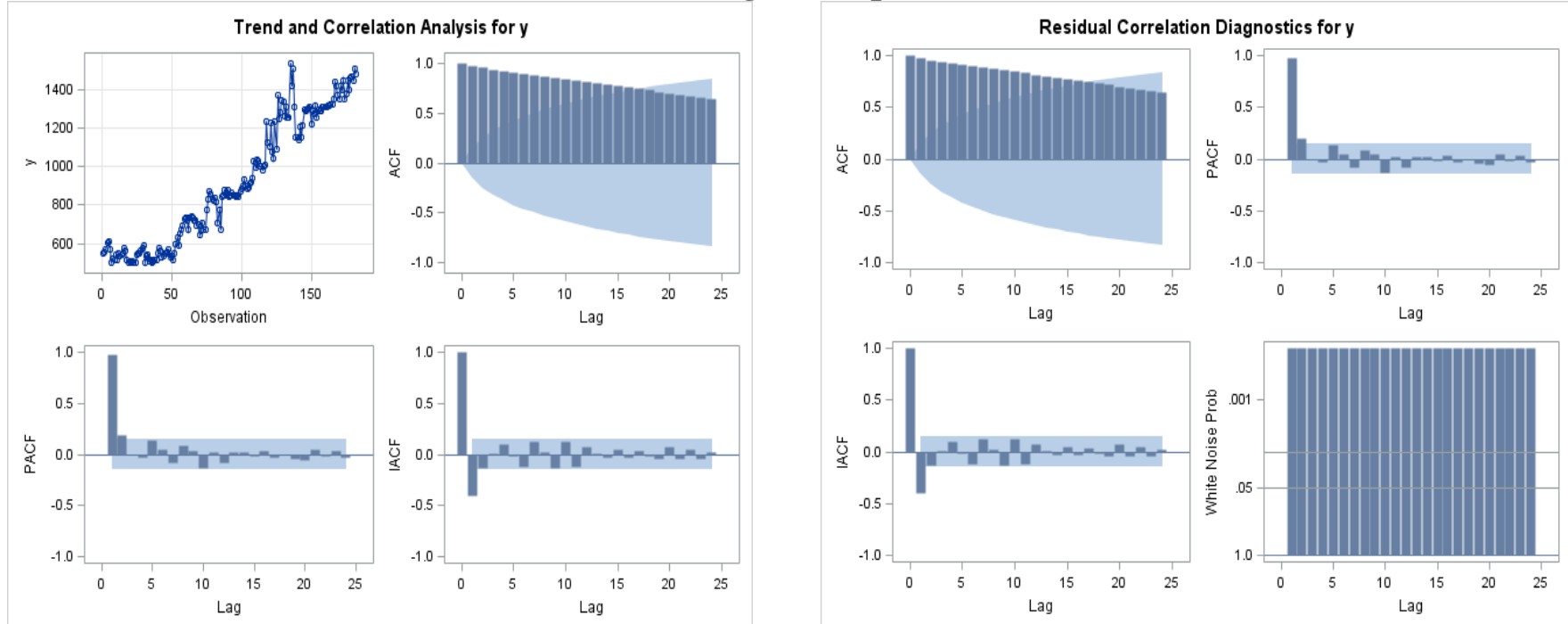

Fig.2 After differencing maize price data

After differencing maize price data

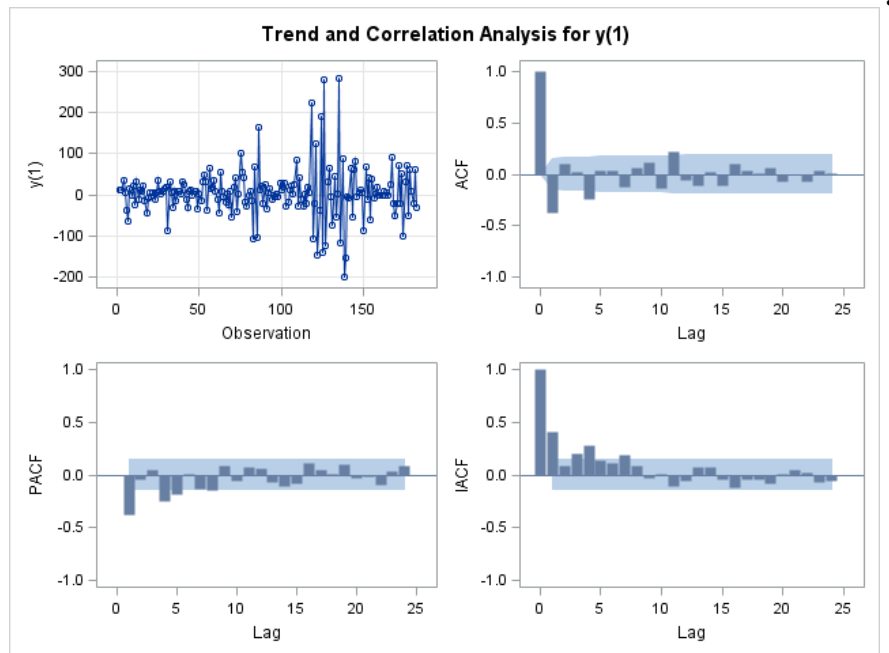

Before differencing residual normality diagnostics
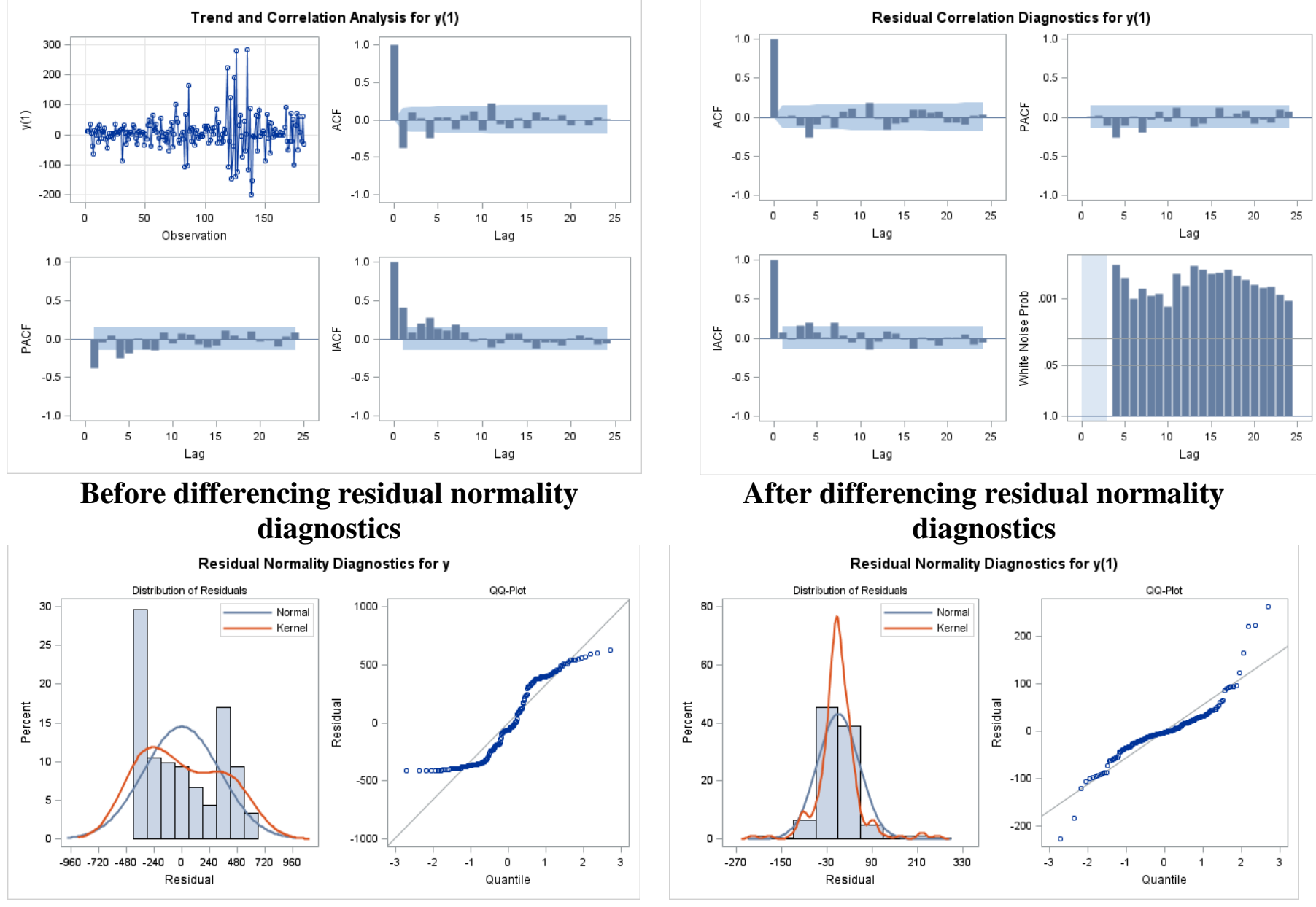

\section{After differencing residual normality diagnostics}

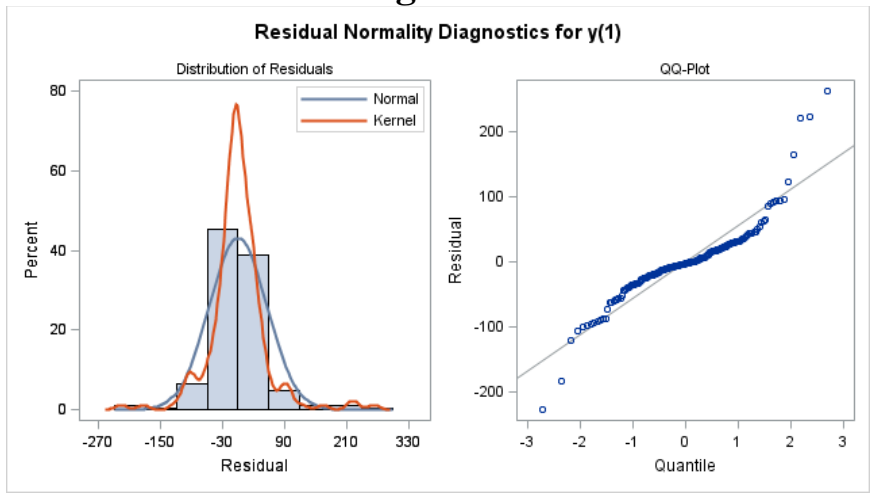


Fig.3 Actual and forecasted prices of maize from April 2002 to May 2017

ARIMA fitting for maize price data

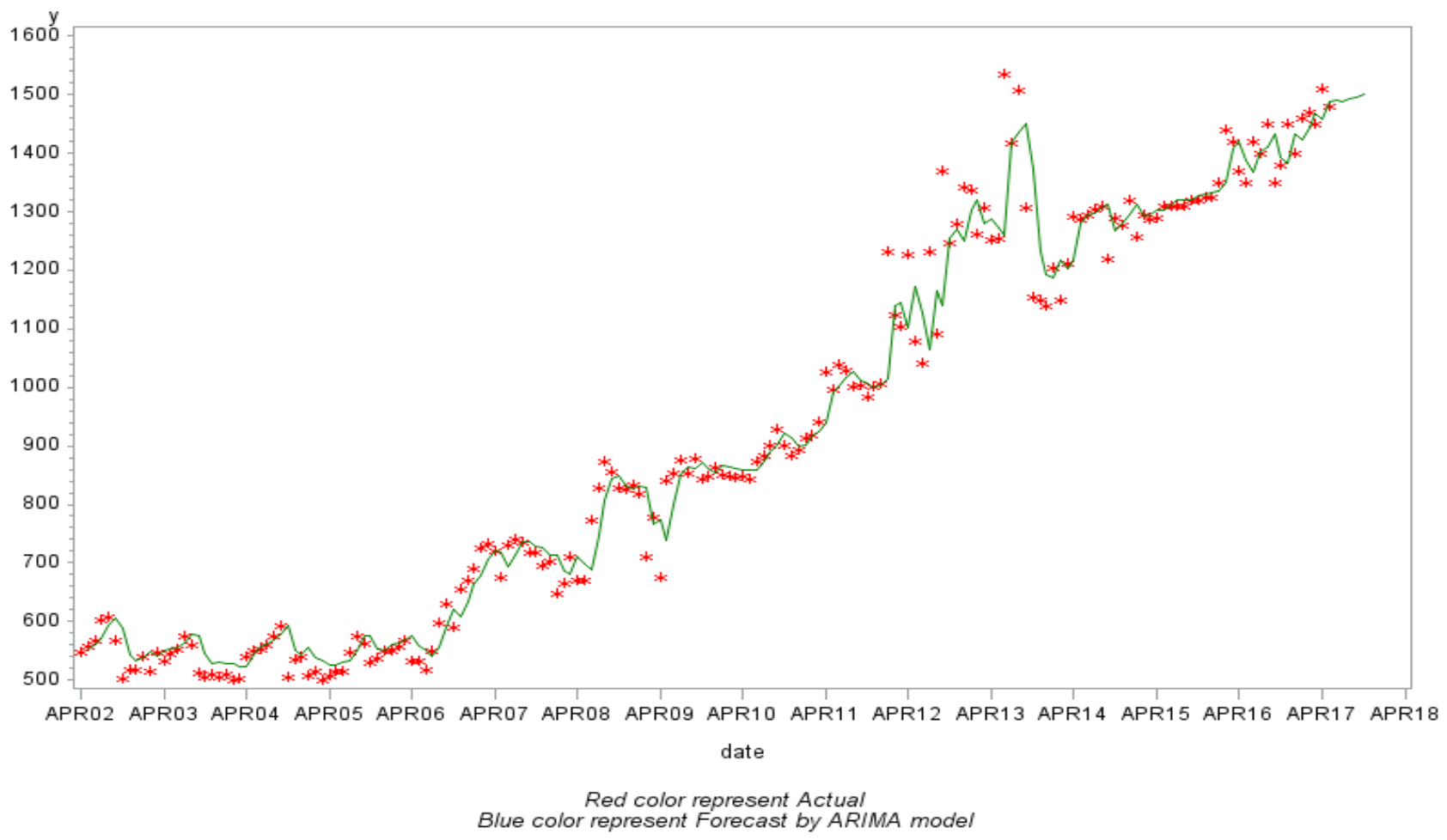

Based on the performance results of different forecasting models, ARIMA 211 was preferred mainly because of the lowest Akaike Information Criterion, lowest Schwarz's Information criterion, Mean Absolute Percentage Error (MAPE) and parameters significant at $1 \%$ level of significance. ARIMA 211 results revealed that price forecasting of maize for the next five months i.e. October to February as followed Rs. 1496, 1500, 1502, 1512, 1513 per quintal respectively.

The results indicate that Autoregressive Integrated Moving Average models ARIMA (211) is the most adequate and efficient model. The ARIMA 211 model results revealed that price forecasting of maize for next five months i.e. October to February as followed Rs. 1496, 1500, 1502, 1512, and 1513 per quintal respectively.
The forecasted results suggest that there are expectations of increasing maize prices in Badepalli regulated market next five months i.e., October to February. This requires the government to take appropriate measures to ensure that farmers and end user get benefited.

\section{References}

Bharathi, R., Havaldhar, Y.N., Megeri, S.N and Patil, G.M. 2009. Forecasting of arrivals and prices in Ramnagar and Siddlagatta market. Journal of the Indian Society of Agricultural Statistics. 63(3). 247-257.

Prajneshu, Ravichandran, S. and Savita. 2002. Structural time series models for describing cyclical fluctuations. Journal of the Indian Society of Agricultural Statistics. 55(1): 70-78. 
Pankratz, A. (1983). Forecasting with univariate Box - Jenkins models: concepts and cases, John Wiley, New Paul, R. K. and Das, M. K. Statistical modelling of inland fish production in India (2010).Journal of the Inland York. Fisheries Society of India, 42(2), 1-7.

\section{How to cite this article:}

Venkatesh Panasa, R. Vijaya Kumari, G. Ramakrishna and Kaviraju, S. 2017. Maize Price Forecasting Using Auto Regressive Integrated Moving Average (ARIMA) Model. Int.J.Curr.Microbiol.App.Sci. 6(8): 2887-2895. doi: https://doi.org/10.20546/ijcmas.2017.608.345 